\title{
Immigrant settlement patterns, transit accessibility, and transit use
}

\author{
Jeff Allen*,1, Steven Farber ${ }^{2}$, Stephen Greaves ${ }^{3}$, Geoffrey Clifton ${ }^{3}$, Hao Wu ${ }^{4}$, \\ Somwrita Sarkar ${ }^{5}$, \& David M. Levinson ${ }^{4}$ \\ *Corresponding Author (jeff.allen@utoronto.ca) \\ ${ }^{1}$ Department of Geography \& Planning, University of Toronto, Canada \\ ${ }^{2}$ Department of Human Geography, University of Toronto Scarborough, Canada \\ ${ }^{3}$ Institute of Transport and Logistics Studies, University of Sydney Business School, The Uni- \\ versity of Sydney, Australia \\ ${ }^{4}$ School of Civil Engineering, The University of Sydney, Australia \\ ${ }^{5}$ School of Architecture, Design, and Planning, The University of Sydney, Australia
}

\begin{abstract}
:
Public transit is immensely important among recent immigrants for enabling daily travel and activity participation. The objectives of this study are to examine whether immigrants settle in areas of high or low transit accessibility and how this affects transit mode share. This is analyzed via a novel comparison of two gateway cities: Sydney, Australia and Toronto, Canada. We find that in both cities, recent immigrants have greater levels of public transit accessibility to jobs, on average, than the overall population, but the geography of immigrant settlement is more suburbanized and less clustered around commuter rail in Toronto than in Sydney. Using logistic regression models with spatial filters, we find significant positive relationships between immigrant settlement patterns and transit mode share for commuting trips, after controlling for transit accessibility and other socio-economic factors, indicating an increased reliance on public transit by recent immigrants. Importantly, via a sensitivity analysis, we find that these effects are greatest in peripheral suburbs and rural areas, indicating that recent immigrants in these areas have more risks of transport-related social exclusion due to reliance on insufficient transit service.
\end{abstract}

\section{Keywords:}

immigrants, public transit, accessibility, mode share

This manuscript preprint version is made available under the CC-BY-NC-ND 4.0 license: http:// creativecommons.org/licenses/by-nc-nd/4.0/

The final published version in the Journal of Transport Geography can be found at https:// doi.org/10.1016/j.jtrangeo.2021.103187.

This paper was also presented at the World Symposium on Transport and Land Use Research (WSTLUR), August 9-11, 2021 


\section{Introduction}

People migrate in search of a better life. Gateway cities, such as Sydney and Toronto, are hubs for international migration and settlement because of their agglomeration of social, cultural, and economic resources. Historically, immigrants settled near and within the centres of these cities, but alongside trends of decentralization of poverty over the past several decades, immigrant settlement and ethnic enclaves are increasingly forming in more auto-oriented suburban neighbourhoods (Johnston, Forrest, \& Poulsen, 2001; Bauder \& Sharpe, 2002; Ehrenhalt, 2012; Vezina \& Houle, 2017). Suburban immigrant settlement patterns could thus result in barriers to accessing destinations by transit as many of these neighbourhoods are more poorly served by transit compared to centrally located neighbourhoods. Since inaccessibility is a key determinant of transport-related social exclusion (Lucas, 2012), and that barriers to activity participation can hinder the settlement process and well-being of newcomers (Farber et al., 2018), it is critical to understand the geography of immigrant settlement patterns relative to transit accessibility.

Accordingly, the first objective of this paper is to map where and to what extent recent immigrants are settling in areas of better or worse transit accessibility compared to settled populations. Building upon and connecting research on the geographies of immigrant settlement patterns (Bauder \& Sharpe, 2002; Randolph \& Tice, 2014; Vezina \& Houle, 2017) and comparative transit accessibility analyses (Allen \& Farber, 2019b; Wu et al., 2021), we study this via an analysis of Sydney and Toronto. These two cities are the largest in their respective nations and have experienced substantial waves of immigration throughout their histories, but vary in terms of their transport and housing geographies as well as their spatial and historical patterns of immigrant settlement. By quantifying how many newcomers live within areas of different levels of transit accessibility, we also contribute evidence that can be used to examine the efficacy of newcomer settlement programs, housing policies, and suburban transit expansion strategies.

The second objective of this paper is to examine transit use among immigrant populations and how this varies for immigrants living in neighbourhoods with different levels of transit accessibility. The availability and quality of public transit service is essential for many recent immigrants by providing the means to travel to destinations that enable societal participation. Delays in obtaining driver's licenses and limited financial resources to purchase private vehicles are often cited as reasons for increased transit reliance among immigrants (Heisz \& Schellenberg, 2004; Blumenberg \& Smart, 2010; Smart, 2015). Importantly, how we interpret immigrants being more reliant on public transit is modified by the geographies of immigrant settlement patterns. For example, the implications of higher reliance on transit, despite being served with poor levels of transit service, can be considered a source of social inequality that may contribute to social exclusion risks. To achieve our second objective, we employ stratified regression models that allow us to assess the difference in transit reliance between immigrants and settled populations, across different levels of transit accessibility.

This paper is structured around analysis aimed at achieving our two main objectives. In the next section we provide a literature review introducing key concepts in immigrant settlement patterns, transit accessibility, and transit use. We next present the study areas and associated datasets used in our analyses. We then present the results of our analysis. And lastly, we conclude by discussing implications of our findings, research limitations, and directions for future work. 


\section{Background}

\subsection{Immigrant settlement patterns}

People immigrating into early-industrializing nations disproportionately settle in 'gateway' cities, like Toronto and Sydney (Hiebert, 2000; Castree, Kitchin, \& Rogers, 2013). These cities are attractive since they provide an abundance of job opportunities and education programs ranging from language classes, vocational programs, and universities. Over time, these cities have accumulated immigrants, resulting in the growth of ethnic and cultural enclaves and communities that provide social networks and social capital that newer migrants can draw upon (Massey, 1985). Such social agglomeration also leads to the growth of culturally specific retail and businesses (e.g. groceries, clothing, etc.) and institutions (e.g. places of worship, community centres, government settlement services). These resources usually cluster in certain parts of cities and can further act as pull factors and drivers for residential preferences of migrants into these cities, and specifically into these neighbourhoods (Zhuang \& Chen, 2017; Boese \& Phillips, 2017). Gateway cities are often the most populous regions in their respective nations, and immigration accounts for a substantial part of their continued growth (Ley, 1999).

Immigrant settlement patterns within regions are often a product of their socio-economic geography and the availability of affordable housing. While there is substantial heterogeneity among recent immigrants in terms of income and wealth, immigrants to Canada and Australia, on average, have less income and fewer financial resources than non-immigrants (Lo, Shalaby, \& Alshalalfah, 2011; Statistics Canada, 2016a; Australian Bureau of Statistics, 2016a). Several studies have shown strong spatial correlations between immigrant settlement and poverty concentration in cities (Kazemipur \& Halli, 2000; I. H. Burnley, 2001). Over the last 50 years, many cities have witnessed trends of suburbanization of poverty (Kneebone \& Garr, 2010; Ehrenhalt, 2012; Hochstenbach \& Musterd, 2018). Specifically, research has shown an increase in low-income residents as well as recent immigrant settlement in auto-oriented suburbs in Canada (Bourne \& Rose, 2001; Vezina \& Houle, 2017; Allen \& Farber, 2021), the United States, (Ehrenhalt, 2012; Farrell, 2016), and Australia (Randolph \& Tice, 2014; Mulley, Ma, Clifton, \& Tanner, 2017) over the past several decades. Some studies have also highlighted trends that more affluent recent immigrants are directly settling in new, more expensive, suburban developments indicating preference for suburban living and car-ownership, while lower-income recent immigrants are settling more in older, more affordable, apartments in the middle suburbs (Hiebert, 2000; Lo et al., 2011). Overall, immigrant enclaves in auto-oriented suburban neighbourhoods are emerging in gateway cities across many early-industrializing nations (Johnston et al., 2001; Bauder \& Sharpe, 2002; Ehrenhalt, 2012). Despite knowledge of the emergence of suburban immigrant enclaves, there have been few studies that attempt to understand the disadvantages caused by transit inaccessibility, particularly in environments where the norms of daily life activity participation are predicated on automobile use.

\subsection{Immigrants and public transit}

Many immigrants living in suburban and rural locations face increased barriers to daily travel due to limited transit service, lack of car ownership, and automobile-oriented neighbourhood

design that impedes active travel, particularly when compared to centrally located neighbour- 
hoods (Clark \& Wang, 2010; Tal \& Handy, 2010; Farber et al., 2018). Research has highlighted difficulties for recent immigrants to travel to supermarkets, education including language classes, health care, and to visit friends and family (Asanin \& Wilson, 2008; Bose, 2014; Farber et al., 2018). These geographic and transport barriers can also compound with specific needs of immigrants such as accessing culturally specific grocery stores (Farber et al., 2018) or health care providers who share a common language (Wang, 2007; Asanin \& Wilson, 2008).

Several studies have made normative arguments for improving levels of transit accessibility for lower socio-economic groups and neighbourhoods (Lucas, 2012; Martens, 2016), and specifically for immigrant communities who are reliant on public transit for daily travel (Amar \& Teelucksingh, 2015). However, there are only a few comparative studies that examine how the geography of immigrant settlement patterns is related to transit accessibility. Transit accessibility can be understood as the ability to reach activity destinations (e.g. jobs, education, services, etc.) by public transit in a reasonable amount of time and is often used to assess quality of transit service across different spatial contexts (Geurs \& Van Wee, 2004; El-Geneidy \& Levinson, 2006; Levinson \& Wu, 2020; Wu \& Levinson, 2020; Wu et al., 2021). Liu and Painter (2012) found that immigrants in US cities have a greater spatial mismatch between residential location and employment than the white native-born population, but less so than the black native-born population. In another study comparing 17 European cities, Bartzokas-Tsiompras and Photis (2019) found that overall, immigrants have better access to rapid transit and commuter rail stations than native-born populations. Similar results were found in Canadian cities in comparing immigrant settlement patterns to transit access to jobs, but despite overall vertically equitable results, Allen and Farber (2019b) estimated that 500,000 recent immigrants in Canada (from 2011 to 2016) lived in areas of low transit access to employment. These studies were either limited by aggregate county-level geographic analysis (Liu \& Painter, 2012), did not directly assess access to activity destinations by public transit (Bartzokas-Tsiompras \& Photis, 2019), or only summarized results for all immigrants at the city level (Allen \& Farber, 2019b) rather than analyzing trends for different communities. Our study builds upon this research to further understand the connections between immigrant settlement patterns and transit accessibility via an international comparison of two gateway cities.

There are also several studies that have directly modelled the relationship between immigration and transit mode share, finding that transit use is higher among immigrants than nonimmigrants (Heisz \& Schellenberg, 2004; Blumenberg \& Evans, 2010; Lo et al., 2011; Smart, 2015). But transit use is likely to decline the longer an immigrant has settled (Blumenberg \& Evans, 2010). Immigrants are also more likely to use active modes and rely on carpooling than non-immigrants (Blumenberg \& Smart, 2010; Smart, 2015; Shin, 2017). A limitation of much of this existing research on transit mode share among recent immigrants is that it does not control for fine-grained measures of transit accessibility, which could be a confounding factor since immigrants are often more likely to initially settle in areas of high transit accessibility (e.g. due to preferences to live near transit). There are studies that find significant positive effects of transit accessibility on neighbourhood-level transit mode share, but these have either not considered recent immigrants in their models (Moniruzzaman \& Páez, 2012; Owen \& Levinson, 2015; Wu, Levinson, \& Owen, 2019), or if they have, it is combined with other variables into a general index of social deprivation, limiting the ability to specifically look at the effects of recent immigrant status (Cui, Boisjoly, Miranda-Moreno, \& El-Geneidy, 2020). Extending this research, we aim to uncover the effects immigrant communities have on transit use, independent of transit accessibility; and further, how these effects potentially vary across different strata of transit accessibility. Such findings can provide important knowledge about the travel conditions and 
burdens experienced by immigrant communities that live in different urban contexts.

\section{Study Areas \& Data}

\subsection{Regional context}

Our study examines two gateway cities: Sydney, Australia and Toronto, Canada. Each are the largest cities in their respective nations, and have witnessed similar trends of immigration throughout their histories. Both were colonized by the British and predominately received immigrants from Great Britain and Ireland during the 19th century. The Canadian Immigration Act of 1910 and the 1901 "White Australia Policy" explicitly excluded immigrants from nonEuropean origins up until the mid-20th century when both nations drastically changed their immigration polices shifting from those based on race and ethnic origin to those based on education and economic potential (Fukuyama \& Gocek, 2019). Since then, there has been a substantial increase in immigration from East Asia and the Global South (Ley, 1999; Boyd \& Vickers, 2000; I. H. Burnley, 2001). At the regional level, this has resulted in an overall increasing cultural and ethnic diversity of immigrants over time (Ley, 1999; Hiebert, 2000; Bauder \& Sharpe, 2002). While each city has become more multicultural overall, there are a number of ethnic and immigrant enclaves clustered within certain boroughs and municipalities (e.g. Vietnamese in Marrickville and Lebanese in Turrella in Sydney; Chinese in Markham and Italians in Vaughan in the Toronto region). Variation of immigrants in terms of class and income has also widened over the past several decades (Ley, 1999), ranging from refugees and asylum seekers to high-income and highly-skilled economic immigrants. These overall changes are due to a combination of global economic and political trends as well as alterations in national immigration policies (Green \& Green, 1999; Hiebert, 2000; Good, 2005). While a few other smaller cities in Canada (e.g. Winnipeg) and Australia (e.g. Perth) are increasing in their share of recent immigrants, Sydney and Toronto remain sizable immigrant destinations in their respective countries. According to the respective 2016 censuses, $42 \%$ of Sydney residents and $46 \%$ of Toronto residents were born overseas putting them both in the top 10 cities in the world in terms of foreign-born populations.

While somewhat similar in historical trends, Sydney and Toronto are quite different geographically (see Figure 1). Both are bordered by a large body of water, but Sydney is also bifurcated by the Sydney Harbour and Parramatta River. Toronto is not topographically divided. In terms of urban form, Toronto is primarily arranged in a grid, which also forms the structure of it's transport network. Sydney's urban form and transport geography is more radial, partly following its more rugged and varied terrain. Each city has light rail, commuter rail, and an extensive network of local buses. Commuter rail lines in both cities are radially focused for commuting trips to and from their respective cores and are slowly being upgraded to include more stops and shorter headways. Sydney's light rail service comprises three lines while Toronto's light rail, colloquially referred to as "streetcars", consists of 10 routes but only a minority of which run on dedicated rights-of-way. Toronto also has a four-line grade-separated rapid transit network that collectively forms the main arteries for its surface routes. In Toronto, each regional municipality operates its own surface transit service, while in Sydney the State of New South Wales operates most rail and bus services complemented by private operation of the light rail and some express bus services. 


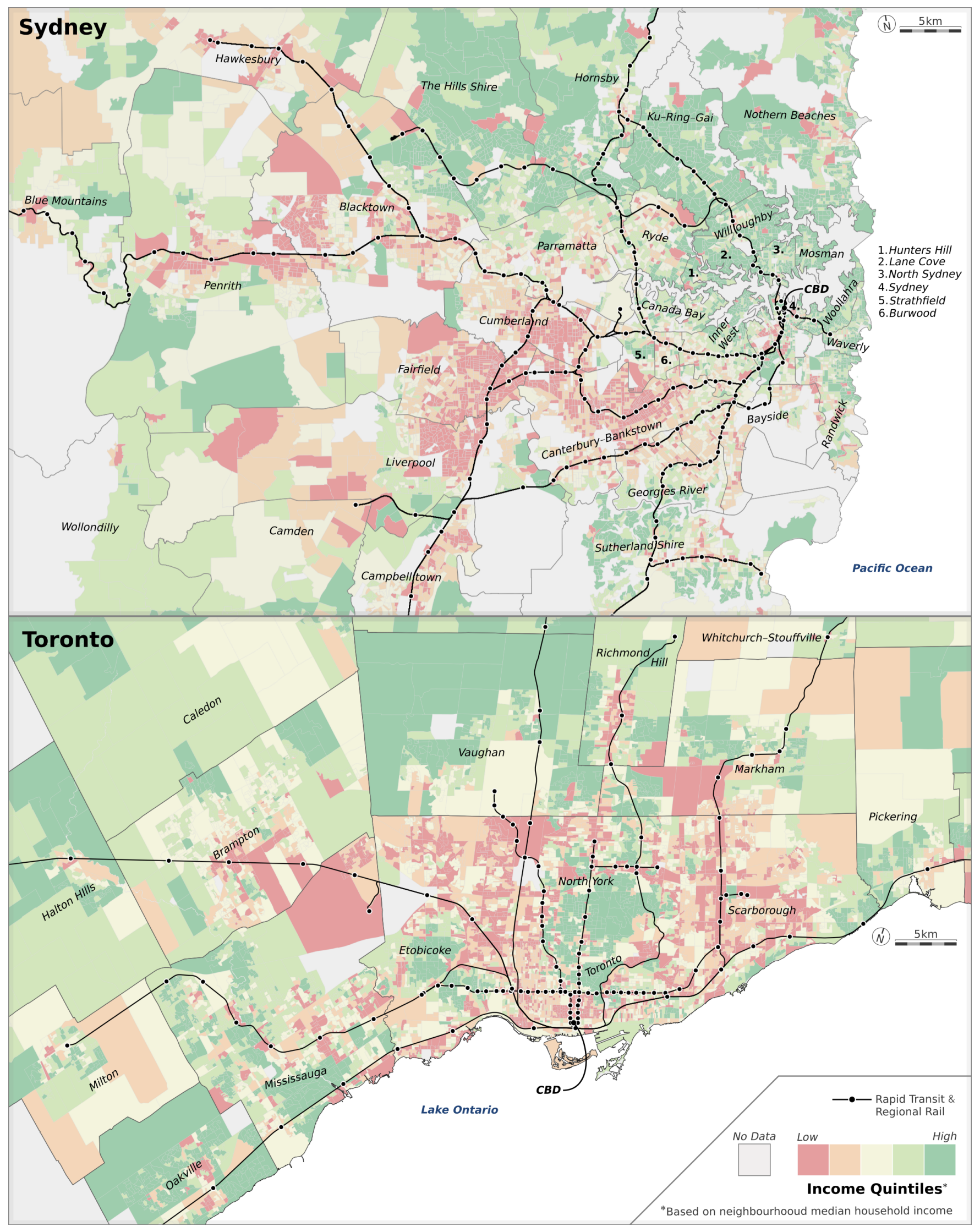

Figure 1: Maps of Sydney and Toronto with major rapid transit lines and income quintiles 
Both cities have an historical core that remains the prime centre of employment and activity. They have also both undergone polycentric development over the past several decades, with urban centres emerging in more suburban locations (Sarkar, Wu, \& Levinson, 2020). These suburban centres however tend to have fewer transit connections and are typically reached more via car than public transit, compared to their historical cores (Xi, Allen, Miller, Farber, \& Keel, 2020).

Importantly, both cities have also witnessed trends of inner-city gentrification and suburbanization of poverty over the past several decades (Ades, Apparicio, \& Seguin, 2012; Randolph \& Tice, 2014; Allen \& Farber, 2021), and a few studies have noted how the geography of recent immigrant settlement in these cities have decentralized as well (Johnston et al., 2001; Bauder \& Sharpe, 2002; Vezina \& Houle, 2017). Contributing to growing trends of suburbanization of poverty among immigrant households is the rising costs of housing in both cities. According to HousingAnywhere (2020), Sydney and Toronto are currently the 11th and 13th most expensive cities in the world, respectively. Importantly, there are insufficient housing supports in place in either city, for example evidenced long wait lists for public housing in Toronto (Gibson, 2021) and financialisation of apartment housing in Sydney (Morris, 2018). This can create extreme economic pressures on recent immigrants, especially those arriving with little wealth or high earning potential after resettlement (Hiebert, 2017)

The housing market in Sydney is characterised by a predictable density gradient, with outer suburbs dominated by low density detached housing, and as one moves closer to the core, increasing density in the form of medium to high-rise apartment blocks and townhouses. Sydney's higher density rental housing is also especially concentrated along railway corridors that provide connectivity to Sydney's Central Business District (Randolph, 2006; Troy, Randolph, Pinnegar, Crommelin, \& Easthope, 2020). In Toronto, there is apartment housing along some major transit corridors, but many of the regional rail stations in Toronto are surrounded by surface parking lots that promote park-and-ride trips in lieu of direct transit-oriented development (Farber \& Marino, 2017). Toronto has an extensive stock of 20th century apartment towers located in the middle suburbs, often away from major transit corridors (August \& Walks, 2018). In Sydney, affordable housing in the middle suburbs consists more of a mix of detached housing, townhouses (e.g. duplexes), and low-rise apartment buildings built in the latter half of the 20th century.

The specific study area for Sydney is its Greater Capital City Statistical Area (GCCSA), while for Toronto, the study area is its Census Metropolitan Area (CMA). Both are defined as agglomerations of smaller census output areas based on their labour force's journey to work flows from the previous census. For both the CMA and GCCSA boundaries, inclusion of smaller census areas into these regional definitions is based on whether over $50 \%$ of the employed labour force commutes to or from nearby areas within the CMA and GCCSA definitions (Australian Bureau of Statistics, 2016c; Statistics Canada, 2016c).

\subsection{Data Sources}

The key variables in our analysis are transit accessibility, immigrant settlement, and transit mode share for work trips (see Table 1). Data for immigrant status, settlement locations, and transit mode share are from the national censuses of Australia and Canada. Fortunately for the 
sake of our research, Australia and Canada operate quinquennial censuses in parallel (a relic of their shared British colonial histories). The most recent census in both nations was in 2016. Each nation's census includes tabulations of immigrants who arrived in the past five years (from the beginning of 2011 up to when the census was collected in 2016). There is a slight variation of tabulations between these two nations due to the time of year when the census is conducted. In Canada, the census is collected in May, in Australia, it is collected in August (Australian Bureau of Statistics, 2016b; Statistics Canada, 2017). To allow for a direct comparison, we also calculate a monthly rate of immigration. Also to note is that census data is based on the home location of residents on the date of the census, but it does not include information about where recent immigrants may have lived between arriving and the census collection date. For both nations, transit mode share is defined as self-reported usual commute mode (non-work trips are not reported in either census). For Canada, mode categories are mutually exclusive, and trips using multiple modes of transport are grouped based on the mode that covers the greatest distance. In Australia, the census does report multi-modal trips by mode, however we do not know the distance of each trip component so we cannot directly match to the Canadian definition. Instead, for our study, we group all trips that have a transit leg in Sydney into a single group. This is based on the assumption that the transit leg generally covers a greater distance than other modes within a multi-modal trip.

Table 1: Summary statistics for Sydney and Toronto

\begin{tabular}{lrr}
\hline & Sydney & Toronto \\
\hline Population 2016 (1000s) & 4,823 & 5,863 \\
Area $\left(\mathrm{km}^{2}\right)$ & 12,368 & 5,906 \\
Overall population density $\left(\right.$ per $\left.\mathrm{km}^{2}\right)$ & 390 & 993 \\
Mean neighbourhood population density $\left(\text { per km }{ }^{2}\right)^{*}$ & 5,663 & 8,512 \\
Mean immigrants per month $(2011-2016)$ & 5,497 & 5,547 \\
Jobs 2016 (1000s) & 2,209 & 2,566 \\
Mean vehicles per household & 1.55 & 1.41 \\
Mean one-way commute time (minutes)* & 35.6 & 34.0 \\
Mean transit accessibility to jobs 2016 (1000s) & 199 & 188 \\
Transit mode share 2016 (journey to work)* & $21.5 \%$ & $24.3 \%$ \\
\hline
\end{tabular}

*Weighted by the neighbourhood population

Census data in Sydney are aggregated to Statistical Areas Level 1 (SA1) and data in Toronto are aggregated to Dissemination Areas (DA). Both sets of geographic units typically comprise a few city blocks, but are larger in areas of lower population density (e.g. in rural, commercial, or industrial areas). DAs are larger than SA1s on average (the average population of a DA in our study area is 779, while for SA1s the average population is 432). For both regions, these are the smallest geographic zones for which socio-economic census data are publicly available.

\subsection{Measuring Transit Accessibility}

To gauge transit accessibility, we use place-based measures of accessibility to jobs. These types of measures are commonly computed to assess the equity and distribution of transport networks (Hansen, 1959; Geurs \& Van Wee, 2004; Levinson \& Wu, 2020). This is formalized as follows. 


$$
A_{i}=\sum_{j} O_{j} f\left(t_{i, j}\right)
$$

$A_{i}$ is the measure of accessibility for zone $i, t_{i, j}$ is the travel time by transit from a zone $i$ to a zone $j$, and $O_{j}$ is the number of jobs in $j$. Data for the number of jobs by zone is also sourced from the Australian and Canadian censuses, respectively, but it should be noted that a limitation is that these data are likely missing locations of informal employment. For our study, $f\left(t_{i, j}\right)$ is a cumulative function that returns 1 if $t_{i, j}$ is less than or equal to 45 minutes, and returns 0 if $t_{i, j}$ is greater than 45 minutes (i.e. the measure can be understood as the number of jobs reachable in a 45 minute transit trip).

$$
f\left(t_{i, j}\right)=\left\{\begin{array}{lll}
1 & \text { if } & t_{i, j} \leq 45 \\
0 & \text { if } & t_{i, j}>45
\end{array}\right.
$$

Cumulative measures are highly correlated with gravity measures and are often selected for analysis because of their ease of interpretation, particularly when comparing between regions (El-Geneidy \& Levinson, 2006; Wu et al., 2021). They have also been used in previous studies examining the relationship between accessibility and mode share (Owen \& Levinson, 2015; Lussier-Tomaszewski \& Boisjoly, 2021). 45 minutes was chosen as a threshold as it is approximate to the mean one-way commute time by public transit in both cities (Statistics Canada, 2016b; Moovit Insights, 2020). 45 minutes has also been found to be an upper limit for how long transit commuters can tolerate a one-way commute (Huang, Levinson, Wang, Zhou, \& Wang, 2018). Travel times by transit, $t_{i, j}$, were computed using OpenTripPlanner and include walking to and from stops, waiting, and all in-vehicle travel times. Accessibility measures are averaged over a morning commute period (7:45am to 8:15am) to account for time deviations caused by fluctuating transit schedules. These measures were computed for SA1 and DA geographies in Sydney and Toronto, respectively, so they could be linked to the aforementioned census data.

\section{Results}

\subsection{Transit Accessibility and Immigrant Settlement Patterns}

First, we compare levels of transit accessibility for recent immigrants with the overall population in both cities. Means and distributions of each are displayed in Figure 2. The area under each curve sums to 1 . Distributions of accessibility are positively skewed, as transit benefits are concentrated within centrally located neighbourhoods with ample transit supply and job proximity. Both cities also have swaths of lower-density suburban areas with minimal levels of transit service. For both regions, recent immigrants, on average, have greater levels of transit accessibility than the overall population, but this gap is much greater in Sydney than in Toronto.

To examine further, we create a bivariate map showing the distributions of the locations of recent immigrant settlement vis-à-vis transit accessibility in each region. This is shown in Figure

3. Greens and purples are areas with higher levels of transit accessibility and whites and pinks 
have lower levels of transit accessibility. In both cities, transit accessibility clusters in the centre, and flows out radially from the core, partially following major transit lines. The dark purple areas are where there are high densities of recent immigrants in areas of high levels of transit accessibility, while the brighter pink areas are those where there are high densities of recent immigrants with lower levels of transit accessibility.

Sydney

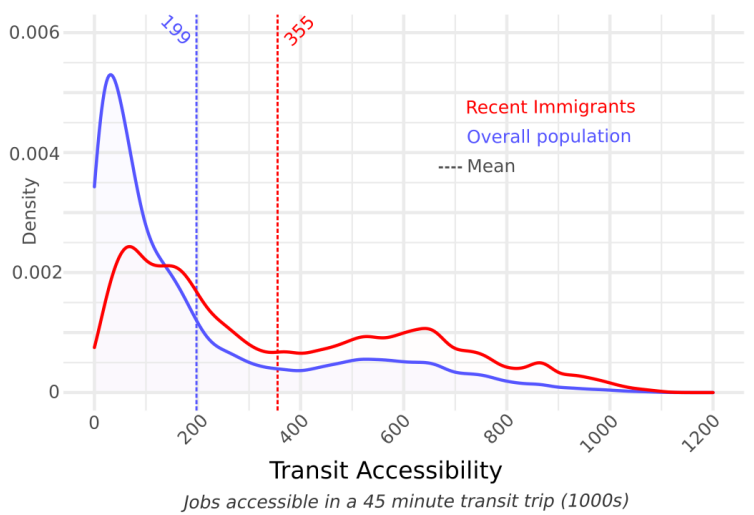

Toronto

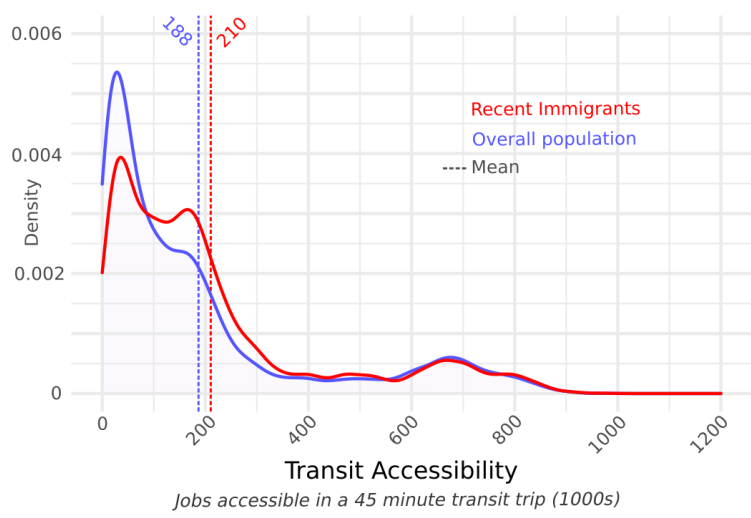

Figure 2: Distribution of transit accessibility for recent immigrants (2011-2016) (red) and the overall population (blue)

Comparing the two maps, we find that in Sydney, locations with high densities of recent immigrants are more clustered along major rail corridors and align more with greater levels of transit accessibility than in Toronto, corroborating the numerical evidence provided in Figure 2. Both cities have high densities of recent immigrants directly within their cores, but there are more neighbourhoods adjacent to the core in Toronto with low densities of recent immigrants than in Sydney. The middle-suburbs of both cities have pockets of high densities of recent immigrants and moderate levels of transit accessibility. In Toronto, this is evident in northern Etobicoke, in Scarborough, and central Mississauga.

In Sydney, only a few of the outer suburbs have large concentrations of recent immigrants. However, these areas vary in terms of their socio-economic status and affordability (Bangura \& Lee, 2019). The higher income Northern suburbs in Sydney, specifically Hornsby and Northern Beaches, likely attract highly skilled and high earning immigrants (I. Burnley, 2005). On the other hand, the western and south-western suburbs of Blacktown and Liverpool have a large amount of relatively affordable rental units as well as moderately priced new housing, and are thus home to middle- to low-income recent immigrants (Bangura \& Lee, 2019). Conversely, the western suburb of Fairfield has high concentrations of very low socio-economic status immigrants, often in overcrowded housing, and with high levels of unemployment (Hunter, 2017). 


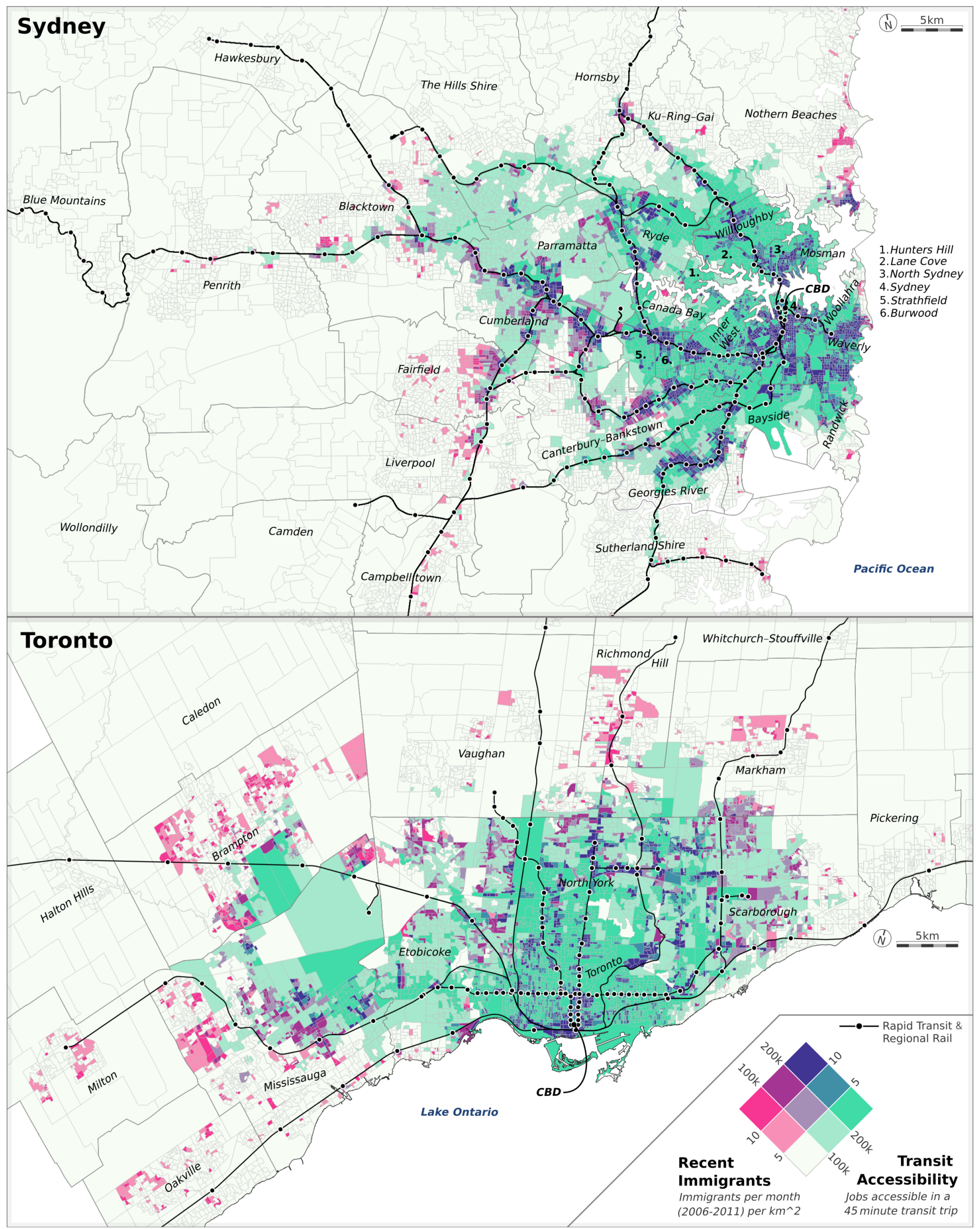

Figure 3: Bivariate maps of transit accessibility and density of recent immigrants 
Toronto, relative to Sydney, has a much higher amount of recent immigrants in outer suburbs, particularly located in the outer municipalities of Brampton, in western Mississauga, as well as parts of Richmond Hill, Oakville, and Milton. These neighbourhoods primarily consist of lower-density suburban development (e.g. detached homes) and auto-oriented environments. The immigrant neighbourhoods in the peripheries of these suburban municipalities are generally higher income, on average, while socio-economic status declines moving inwards (Kazemipur \& Halli, 2000; Ades et al., 2012). The middle-suburbs of Scarborough and in northern Etobicoke are home to a substantial number of lower-income immigrants, many of whom live in aging apartment blocks built during the latter half of the 20th century (August \& Walks, 2018). Most of these neighbourhoods are disconnected from major transit arteries, so transit riders rely on slower surface bus routes to access destinations (Allen \& Farber, 2019b).

The above analysis and figures consider all recent immigrant populations in aggregate. However, immigrants originating from different countries tend to cluster and agglomerate in different parts of cities (Massey, 1985; Zhuang \& Chen, 2017). As such, we further examine how different immigrant groups fare in terms of transit accessibility. Specifically, we compute the mean transit accessibility for immigrants originating from different countries, $c$. This is calculated as a weighted average via:

$$
\bar{A}_{c}=\frac{\sum_{i} A_{i} P_{i, c}}{\sum_{i} P_{i, c}}
$$

where $P_{i, c}$ is the population in a zone $i$ who have recently immigrated from $c$. Secondly, we compute a ratio comparing the mean transit accessibility for immigrants $c$, to the population not in this group $\neg \mathcal{C}$ (non-immigrants and not-recent immigrants):

$$
R_{c}=\frac{\bar{A}_{c}}{\bar{A}_{\neg c}}
$$

Similar ratios have been used to asses how centralized (or suburbanized) a population group is (Zhang \& Pryce, 2020), or for directly analyzing inequities of transport accessibility for different groups (Allen \& Farber, 2019a).

Table 2: Average accessibility $\left(\bar{A}_{c}\right)$ and relative accessibility ratios $\left(R_{c}\right)$ for recent immigrants (2011-2016) from different countries, $c$

\begin{tabular}{llllllll}
\hline & \multicolumn{1}{l}{ Sydney } & & & Toronto & \\
Country of birth $(c)$ & Total $(\%)$ & $\bar{A}_{c}$ & $R_{c}$ & Home country $(c)$ & Total $(\%)$ & $\bar{A}_{c}$ & $R_{c}$ \\
\hline China & $63,500(17.2 \%)$ & 452 & 2.30 & India & $58,800(16.5 \%)$ & 158 & 0.84 \\
India & $43,200(11.7 \%)$ & 311 & 1.57 & China & $49,900(14.0 \%)$ & 188 & 1.00 \\
United Kingdom & $22,100(6.0 \%)$ & 366 & 1.84 & Philippines & $43,300(12.1 \%)$ & 241 & 1.28 \\
Iraq & $12,500(3.4 \%)$ & 144 & 0.72 & Pakistan & $21,800(6.1 \%)$ & 149 & 0.79 \\
Philippines & $12,300(3.3 \%)$ & 271 & 1.36 & Iran & $18,800(5.3 \%)$ & 271 & 1.44 \\
South Korea & $11,000(3.0 \%)$ & 453 & 2.28 & Iraq & $8,200(2.3 \%)$ & 138 & 0.73 \\
New Zealand & $10,800(2.9 \%)$ & 258 & 1.29 & USA & $8,000(2.2 \%)$ & 258 & 1.38 \\
Pakistan & $10,400(2.8 \%)$ & 227 & 1.14 & Jamaica & $7,300(2.1 \%)$ & 149 & 0.80 \\
Vietnam & $9,600(2.6 \%)$ & 254 & 1.27 & Sri Lanka & $7,400(2.1 \%)$ & 134 & 0.71 \\
Iran & $7,800(2.1 \%)$ & 255 & 1.28 & Bangladesh & $6,800(1.9 \%)$ & 317 & 1.69 \\
\hline All immigrants & $370,100(100 \%)$ & 355 & 1.91 & All immigrants & $356,900(100 \%)$ & 210 & 1.13 \\
\hline
\end{tabular}


Results for the top ten originating nations for each region are shown in Table 2. If $R_{c}>1$, then the group tends to settle in zones with greater than average levels of transit accessibility than the overall population. Only Iraqi immigrants in Sydney have worse levels of transit accessibility than the overall population. This is due to the majority of Iraqi immigrants settling in Fairfield in Western Sydney (located about an hour from the CBD) mainly because of existing family links, immigrant communities, and settlement resources (Hunter, 2017). Immigrants from East Asia, particularly China and South Korea, have very high levels of transit accessibility, more than twice the amount of other residents. Conversely, in Toronto, Chinese immigrants have the same levels of transit accessibility as the overall population on average. In Toronto, immigrants from South Asia, particularly from India, Pakistan, and Sri Lanka, have substantially lower levels of transit accessibility on average than the overall population. Many immigrant communities from these nations can be found in the outer suburbs in Brampton and Mississauga. One exception are immigrants from Bangladesh, who are more likely to settle in the inner suburbs of Toronto served with frequent bus service, albeit quite far from rapid transit.

\begin{tabular}{|c|c|c|c|c|c|c|c|c|c|c|c|}
\hline \multirow{2}{*}{\multicolumn{2}{|c|}{ untry of origin }} & \multicolumn{2}{|c|}{ low } & \multicolumn{6}{|c|}{ Decile of transit accessibility } & \multicolumn{2}{|c|}{ high } \\
\hline & & 1 & 2 & 3 & 4 & 5 & 6 & 7 & 8 & 9 & 10 \\
\hline \multirow{11}{*}{ 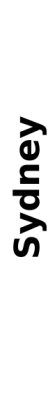 } & China & $0.4 \%$ & $0.6 \%$ & $1.6 \%$ & $2.4 \%$ & $3.9 \%$ & $5.9 \%$ & $11.2 \%$ & $15.9 \%$ & $21.1 \%$ & $37.0 \%$ \\
\hline & India & $0.9 \%$ & $2.2 \%$ & $3.1 \%$ & $3.5 \%$ & $5.2 \%$ & $9.1 \%$ & $14.8 \%$ & $31.4 \%$ & $15.9 \%$ & $13.9 \%$ \\
\hline & United Kingdom & $4.6 \%$ & $4.4 \%$ & $5.7 \%$ & $7.6 \%$ & $6.8 \%$ & $5.8 \%$ & $6.6 \%$ & $11.4 \%$ & $19.3 \%$ & $27.6 \%$ \\
\hline & Iraq & $1.2 \%$ & $3.0 \%$ & $6.5 \%$ & $15.7 \%$ & $25.5 \%$ & $16.5 \%$ & $18.6 \%$ & $6.2 \%$ & $3.3 \%$ & $3.6 \%$ \\
\hline & Philippines & $2.3 \%$ & $4.8 \%$ & $7.1 \%$ & $7.7 \%$ & $9.3 \%$ & $11.5 \%$ & $13.5 \%$ & $15.2 \%$ & $13.8 \%$ & $14.9 \%$ \\
\hline & South Korea & $0.6 \%$ & $1.0 \%$ & $1.9 \%$ & $2.7 \%$ & $3.6 \%$ & $8.2 \%$ & $12.7 \%$ & $16.2 \%$ & $17.3 \%$ & $35.8 \%$ \\
\hline & New Zealand & $3.1 \%$ & $8.5 \%$ & $9.5 \%$ & $9.5 \%$ & $11.3 \%$ & $10.1 \%$ & $10.4 \%$ & $8.9 \%$ & $11.2 \%$ & $17.4 \%$ \\
\hline & Pakistan & $0.7 \%$ & $3.0 \%$ & $4.7 \%$ & $6.0 \%$ & $7.4 \%$ & $16.0 \%$ & $22.0 \%$ & $25.5 \%$ & $8.1 \%$ & $6.5 \%$ \\
\hline & Vietnam & $1.2 \%$ & $1.9 \%$ & $2.8 \%$ & $10.0 \%$ & $18.3 \%$ & $16.0 \%$ & $16.7 \%$ & $9.7 \%$ & $7.6 \%$ & $15.9 \%$ \\
\hline & Iran & $0.8 \%$ & $1.9 \%$ & $3.2 \%$ & $5.6 \%$ & $8.4 \%$ & $14.5 \%$ & $25.7 \%$ & $18.8 \%$ & $9.0 \%$ & $12.0 \%$ \\
\hline & All immigrants & $1.3 \%$ & $2.6 \%$ & $3.9 \%$ & $5.6 \%$ & $7.4 \%$ & $9.1 \%$ & $12.5 \%$ & $16.5 \%$ & $16.6 \%$ & $24.5 \%$ \\
\hline \multirow{13}{*}{$\begin{array}{l}\stackrel{0}{2} \\
\stackrel{2}{0} \\
\text { 인 }\end{array}$} & \multirow[b]{2}{*}{ Country of origin } & \multicolumn{2}{|c|}{ low } & \multicolumn{6}{|c|}{ Decile of transit accessibility } & \multicolumn{2}{|c|}{ high } \\
\hline & & 1 & \multirow{2}{*}{$\frac{\mathbf{2}}{9.3 \%}$} & \multirow{2}{*}{$\frac{3}{1.2 \%}$} & \multirow{2}{*}{$\begin{array}{c}4 \\
16.0 \%\end{array}$} & 5 & 6 & 7 & 8 & \multirow{2}{*}{$\frac{9}{6.3 \%}$} & 10 \\
\hline & India & $4.0 \%$ & & & & $12.7 \%$ & $12.7 \%$ & $12.2 \%$ & $9.0 \%$ & & $6.5 \%$ \\
\hline & China & $4.2 \%$ & $11.6 \%$ & $10.2 \%$ & $7.8 \%$ & $10.1 \%$ & $11.7 \%$ & $14.4 \%$ & $12.0 \%$ & $9.5 \%$ & $8.5 \%$ \\
\hline & Philippines & $2.1 \%$ & $2.7 \%$ & $4.8 \%$ & $4.9 \%$ & $7.2 \%$ & $12.6 \%$ & $16.4 \%$ & $22.6 \%$ & $17.9 \%$ & $8.7 \%$ \\
\hline & Pakistan & $7.4 \%$ & $9.5 \%$ & $8.9 \%$ & $9.0 \%$ & $14.8 \%$ & $12.9 \%$ & $12.0 \%$ & $11.7 \%$ & $10.7 \%$ & $3.2 \%$ \\
\hline & Iran & $3.5 \%$ & $6.3 \%$ & $6.6 \%$ & $7.7 \%$ & $7.5 \%$ & $10.2 \%$ & $8.6 \%$ & $12.9 \%$ & $22.7 \%$ & $13.9 \%$ \\
\hline & Iraq & $7.9 \%$ & $4.5 \%$ & $6.1 \%$ & $4.4 \%$ & $24.4 \%$ & $10.5 \%$ & $17.4 \%$ & $21.0 \%$ & $2.2 \%$ & $1.5 \%$ \\
\hline & USA & $7.2 \%$ & $7.5 \%$ & $10.6 \%$ & $7.3 \%$ & $10.2 \%$ & $8.2 \%$ & $7.7 \%$ & $9.8 \%$ & $12.9 \%$ & $18.5 \%$ \\
\hline & Jamaica & $1.8 \%$ & $8.5 \%$ & $9.7 \%$ & $9.8 \%$ & $16.7 \%$ & $16.8 \%$ & $14.9 \%$ & $12.0 \%$ & $5.6 \%$ & $4.1 \%$ \\
\hline & Sri Lanka & $4.5 \%$ & $7.6 \%$ & $7.3 \%$ & $11.8 \%$ & $14.2 \%$ & $18.1 \%$ & $14.1 \%$ & $15.4 \%$ & $5.8 \%$ & $1.4 \%$ \\
\hline & Bangladesh & $1.8 \%$ & $1.8 \%$ & $3.0 \%$ & $3.6 \%$ & $6.4 \%$ & $10.5 \%$ & $15.9 \%$ & $15.2 \%$ & $23.3 \%$ & $18.6 \%$ \\
\hline & All immigrants & $4.4 \%$ & $7.3 \%$ & $8.0 \%$ & $8.3 \%$ & $10.4 \%$ & $11.7 \%$ & $13.8 \%$ & $14.0 \%$ & $12.5 \%$ & $9.7 \%$ \\
\hline
\end{tabular}

Figure 4: Percent of immigrants within each decile of transit accessibility

While ratios are useful in assessing the overall vertical equity of transit accessibility for recent immigrants, they are limited in their inability to look beyond the mean. For example, even if a group, on average, has a high level of accessibility, there still may be a substantial number living in neighbourhoods with low accessibility (Allen \& Farber, 2019b). Accordingly, we tabulate the percent of recent immigrants who are living in each decile of transit accessibility. These deciles were computed at the zonal level, weighted by the total population in each zone. The percents in each decile are shown in Figure 4. While both cities have immigrants settling in low access 
neighbourhoods, these totals are much greater in Toronto than in Sydney, particularly for Indian and Chinese immigrants. As well, the highest decile of transit accessibility in Sydney is home to a much greater percent of recent immigrants than in Toronto.

\subsection{Immigrant Settlement and Transit Mode Share}

In this section, we analyze whether and where recent immigrants are more likely to use transit than the overall population. Such analysis is important for assessing how travel behaviour and burdens vary for recent immigrants, in part to help inform more nuanced policy that can address differences in urban form and accessibility. Previous studies have noted that recent immigrant status increases the likelihood of travelling by transit (Heisz \& Schellenberg, 2004; Blumenberg \& Evans, 2010; Smart, 2015). However, a limitation of much of this existing research on transit mode share among recent immigrants is that it does not control for comprehensive measures of transit accessibility. But as our analysis above shows, recent immigrants are also more likely to settle in areas of higher transit accessibility on average, which could be a confounding factor when trying to estimate an independent effect of immigrant status partly due to greater preferences among immigrants to select to live near transit. Moreover, existing research does not examine variations in effects within or between regions.

Accordingly, we estimate models examining the effects of transit accessibility and proportion of recent immigrants in a neighbourhood on transit mode share. Our main hypothesis is that neighbourhoods with a relatively higher proportion of recent immigrants have a greater transit mode share, even after controlling for transit accessibility and other socio-economic factors. Transit mode share is measured as the percent of workers in a zone who commute to work by public transit. Other control variables were selected based on previous studies using neighbourhood-level census data to model transit mode share (Owen \& Levinson, 2015; Cui et al., 2020), as well as variable consistency between the Australian and Canadian censuses. We tested linear and quadratic transformations of transit accessibility, since previous research has found non-linear effects of accessibility on mode share (Saxe, Miller, \& Farber, 2017; Cui et al., 2020).

The dependent variable, transit mode share in a zone, is a percentage (bounded by 0 and 1), so we utilize generalized linear regression with a logit link function. The same type of model has been used in previous studies predicting neighbourhood-level transit mode share (Moniruzzaman \& Páez, 2012; Xi et al., 2020). Our models are also weighted by the population in each zone.

In our initially generated models, we found high spatial auto-correlation among the residuals (Moran's $I>0.4, p<0.001$ ). This violates the assumption that model residuals are independent from each other. As such, we used a spatial filtering approach to generate orthogonal latent variables representing map patterns that are inputted into the model (Griffith, 2003). These latent variables likely represent omitted local built environment variables (e.g. pedestrian network connectivity) or other demographic and household characteristics that have a

spatial pattern. For example, we were unable to include car ownership due to lack of data availability in Canada, which likely has a spatial pattern that influences transit mode share. Specifically, these latent variables are the eigenvectors from a modified spatial weights matrix (Queen connectivity) and their selection in the models is determined via step-wise regression 
based on minimizing spatial autocorrelation among residuals as well as limiting co-linearity with the main co-variates $(r<0.25)$. This modelling approach was also previously used by Moniruzzaman and Páez (2012) to assess the effects of transit accessibility on transit mode share in Hamilton, Canada. The model can be represented as follows where $\pi$ is a vector pertaining to the percent of the labour force that regularly commutes by public transit, $X$ is a matrix of independent variables, $S$ is the spatial filtering matrix, $\epsilon$ are residuals, and $\beta$ and $\phi$ are vectors of coefficients.

$$
\ln \frac{\pi}{1-\pi}=\beta X+\phi S+\epsilon
$$

Model coefficients, Odds Ratios (ORs), and adjusted $R^{2}$ for Sydney and Toronto are displayed in Table 3. The coefficients and ORs do not indicate individual level choices, but instead denote the probability that workers within a zone use public transit for their commute. Model fit is assessed using McFadden's pseudo- $R^{2}$ (McFadden, 1974). Resulting $R^{2}$ values are the higher end of those found in similar studies (Owen \& Levinson, 2015; Wu et al., 2019; Cui et al., 2020). Most other studies find $R^{2}$ values within the 0.5 to 0.8 range, while ours were 0.83 and 0.78 , for Sydney and Toronto respectively, partly due to the incorporation of spatial filters (without the spatial filters, the $R^{2}$ was 0.69 for Sydney and 0.65 for Toronto).

Table 3: Logistic regression results for predicting transit mode share in a zone

\begin{tabular}{|c|c|c|c|c|c|c|}
\hline & \multicolumn{3}{|c|}{ Sydney } & & \multicolumn{2}{|c|}{ Toronto } \\
\hline$n$ & \multicolumn{3}{|c|}{10,946} & & \multicolumn{2}{|c|}{7,494} \\
\hline Spatial filters (length of $\phi$ ) & \multicolumn{3}{|c|}{189} & & \multicolumn{2}{|l|}{135} \\
\hline \multirow[t]{2}{*}{ Pseudo $R^{2}$ (McFadden) } & \multicolumn{3}{|c|}{0.83} & \multicolumn{3}{|c|}{0.78} \\
\hline & $\beta$ & OR & & $\beta$ & OR & \\
\hline Intercept & -2.746 & 0.064 & $* * * *$ & -1.743 & 0.175 & $* * *$ \\
\hline Transit access to jobs (100k) & 0.219 & 1.245 & $* * *$ & 0.454 & 1.575 & $* * *$ \\
\hline Transit access to jobs (100k) ${ }^{2}$ & -0.019 & 0.981 & $* * *$ & -0.034 & 0.967 & $* * *$ \\
\hline Percent recent immigrants & 0.017 & 1.017 & $* * *$ & 0.018 & 1.018 & $* * *$ \\
\hline Yearly median household income year (\$10k) & -0.005 & 0.995 & * & -0.038 & 0.963 & $* * *$ \\
\hline Population density $\left(1,000 / \mathrm{km}^{2}\right)$ & -0.001 & 0.999 & $* * *$ & 0.000 & 1.000 & \\
\hline Percent unemployed & 0.003 & 1.003 & & 0.009 & 1.009 & *** \\
\hline Percent renters & 0.008 & 1.008 & $* * *$ & 0.004 & 1.004 & *** \\
\hline Percent moved in the past year & -0.001 & 0.999 & & -0.008 & 0.992 & $* * *$ \\
\hline Percent with post-secondary education & 0.016 & 1.016 & $* * *$ & 0.002 & 1.002 & * \\
\hline Percent elderly $(65+)$ & -0.001 & 0.999 & & -0.007 & 0.993 & $* * *$ \\
\hline
\end{tabular}

Overall, the models show that both transit accessibility and percent of recent immigrants in a neighbourhood positively impact transit mode share for journey to work trips. The recent immigrant effect is very similar when comparing cities, with an OR of 1.017 in Sydney and 1.018 in Toronto. For Sydney, a 1\% increase in the percent of recent immigrants in a zone increases the odds of transit use by $1.7 \%$, all else being equal. There are differences in the significance of the other socio-economic covariates. In Toronto, income, unemployment, and percent elderly are significant factors-while in Sydney, post-secondary education and percent renters in a neighbourhood are significant factors. Transit accessibility, for both cities, has a significant concave quadratic relationship. The maximum of the curve for Sydney is at $A=576,000$ jobs, 
and in Toronto, $A=668,000$ jobs. This level of accessibility corresponds to older, pre-war, residential neighbourhoods just outside of their respective city centres. Transit mode share thus declines away from these neighbourhoods, outwards to more suburban locales, as well as directly within the urban cores, potentially due to active travel becoming more predominant.

We then generate models stratified across each decile of transit accessibility for each study region. This allows us to examine whether recent immigrants are more or less likely to use transit than the overall population, across different levels of transit accessibility (which can also be thought of as a proxy for centralization or suburbanization). This is important for understanding transit reliance, and its associated benefits and burdens, among immigrant communities in different urban contexts.
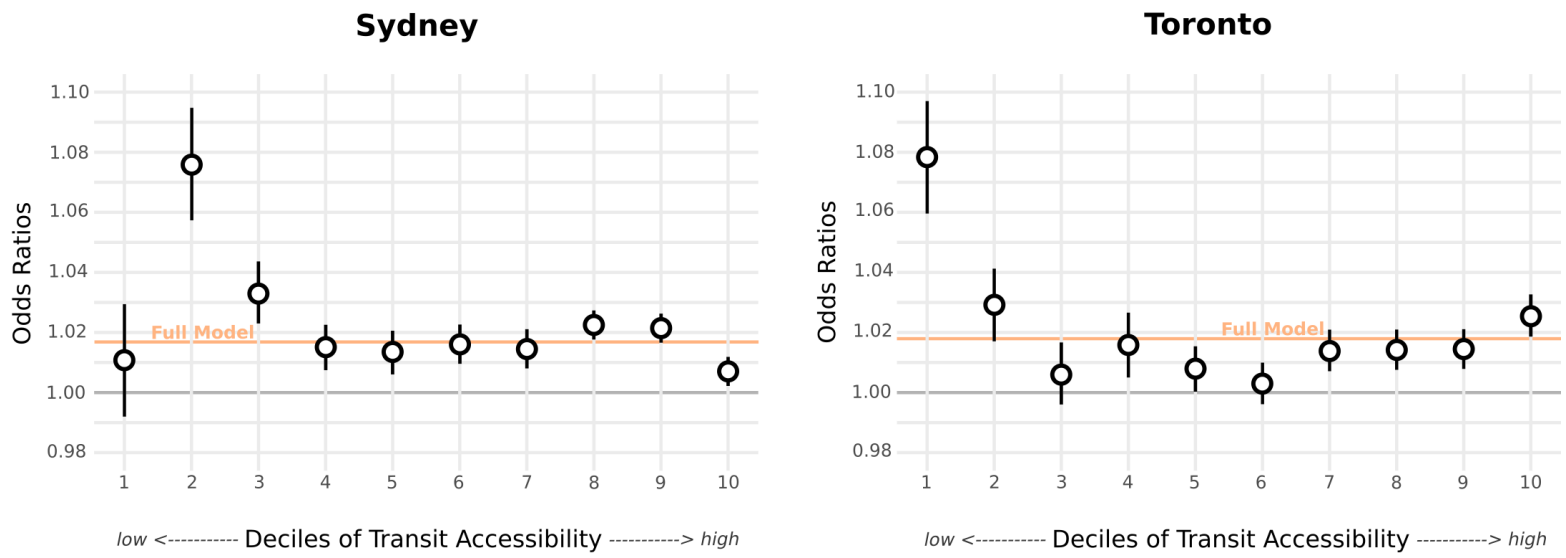

Figure 5: Odds ratios for the effect of recent immigrants on transit mode share stratified across deciles of transit accessibility

Figure 5 displays odds ratios and their confidence intervals for the percent of population in each neighbourhood that are recent immigrants. Initially noticeable in these figures is that the lowest decile in Toronto, and the second lowest in Sydney, by far, have the greatest effect. These levels of accessibility generally pertain to peripheral suburbs, exurban communities, and rural areas. The results therefore show that immigrants on the periphery are far more likely to use transit than non-immigrants. This is indicative that there is increased transit reliance and barriers to car availability, and thus barriers to daily travel, within these peripheral immigrant communities. In Toronto, deciles 3-6 show less of an effect of immigrant status on transit mode share. Neighbourhoods in this range are generally found in mid- to late 20th century suburbs, but not the most distant suburban zones. In Toronto, this generally means these neighbourhoods are at the edge of a the frequent bus network operated by the Toronto Transit Commission. In Sydney, the effect in these middle deciles is closer to the overall effect found in the full model. Another notable difference between the two cities is directly within their cores (decile 10). In the city centre in Toronto (the highest decile), recent immigrants use transit more than in the city centre of Sydney, relative to non-immigrants. This might be an indication that reverse commuting is more prevalent among immigrants in Toronto, while in Sydney, centrally located immigrants may be more likely to work locally (and walk or bike) and thus be less likely to rely on transit. 


\section{Conclusions}

Our analysis provides ample evidence that recent immigrants are more likely to use public transit than the general population, and that this relationship holds in both Sydney and Toronto, two gateway cities with different geographical contexts. We also find that recent immigrants in these two cities tend to live in neighbourhoods with better transit accessibility, on average, than the overall population. However, it is also evident that many recent immigrants reside in neighbourhoods of low transit accessibility in both cities.

Comparing the two cities, recent immigrant settlement in Sydney is more centralized than Toronto; where in the latter, there are relatively more immigrant enclaves in suburban municipalities. This difference could partly be due to there being a much greater abundance of rental apartment housing stock dispersed in the suburbs of Toronto relative to Sydney. In Sydney, recent and current apartment construction has occurred predominately in high-transit-access areas (e.g., Wolli Creek, Green Square) while in Toronto new construction in the highest access areas include a substantial number of condominiums geared to higher-income residents. Another factor could be the distribution of employment. There may be relatively more service sector jobs that attract new immigrants located in the city center in Sydney than Toronto. An important direction for future work would be to examine the specific employment locations of recent immigrants. Another key finding is that when looking at the location of suburban immigrant neighbourhoods, those in Sydney are much more likely to be located along major transit corridors than in Toronto. This is an indication that Sydney has better land-use transportation integration and specifically transit oriented development of housing used by recent immigrants, and that commuter rail in Toronto tends to serve wealthier non-immigrant residents.

In our models, we find that transit use among recent immigrants is greater (relative to nonimmigrants) in neighbourhoods in the lower deciles of transit accessibility in both Sydney and Toronto. This heightened reliance on poor levels of transit service may lead to reduced ability to travel to daily activities, and furthermore, increased risks of social exclusion. For example, previous research has shown that a lack of car ownership combined with poor transit accessibility results in lower activity participation rates, an indicator of transport-related social exclusion (Allen \& Farber, 2020; Barri et al., 2021). Settlement in peripheral neighbourhoods can thus be considered an often overlooked source of social inequality among recent immigrants that could have detrimental impacts on societal participation and upward mobility.

A pertinent direction for future research is the need for longitudinal analyses of immigrant settlement, transit access, and transit use. For one, an historical analysis would be important for knowing whether, and if so, how and where levels of transit accessibility for recent immigrants have improved or worsened over time. This would also compliment existing neighbourhood change research on suburbanization of poverty, particularly in Canadian and Australian cities (Bourne \& Rose, 2001; Ades et al., 2012; Randolph \& Tice, 2014; Allen \& Farber, 2021). Second, extending analysis temporally could be useful in terms of predicting future settlement patterns of recent immigrants, and more specifically, dis-aggregating population growth projections by internal and external migrants. This could allow for equity analyses of future transit and landuse scenarios, as well as serve as more sophisticated inputs into travel demand models, which typically tend to ignore recent immigrant status even though it is a strong predictor of transit demand. 
While our study was focused on neighbourhoods, future research should also conduct individual level analyses. Individual analysis would allow for examining whether and to what extent travel behaviour outcomes such as lengthy commute times or activity participation rates are different for recent immigrants (particularly in suburban locales where there are lower levels of transit accessibility) as well as how travel experiences among immigrants can vary by income and other socio-economic factors (Barajas, Agrawal, \& Chatman, 2018). For example, in our comparative study, we found that in the lowest decile of transit accessibility in Toronto, recent immigrants rely more on transit than in Sydney. For instance, there is evidence in the Toronto region that some exurban areas are home to Syrian refugees who do not have cars (Farber et al., 2018), while in Sydney it might be the case that immigrants in these peri-urban areas have higher incomes and have private vehicles. Individual analysis could also delve into travel for a wider range of activities such a groceries and healthcare (Wang, 2007; Asanin \& Wilson, 2008; Bose, 2014). However, there are data limitations impeding individual analysis at a population level. One of the impediments for doing this within Toronto is that the quinquennial household travel survey has not collected immigration or ethnicity status of respondents. Accordingly, we also recommend increasing the number of socio-economic attributes collected with household travel surveys in order to support transport equity research and policy. Overall, continuing research in these directions, temporally and via dis-aggregation, would build upon our findings on the positive geographical associations between immigrant settlement patterns, transit accessibility, and transit mode share. Doing so would provide further insight into addressing specific travel burdens experienced by recent immigrants.

\section{Acknowledgements}

The authors are grateful for project funding provided by the University of Toronto Office of the Vice President, International.

\section{References}

Ades, J., Apparicio, P., \& Seguin, A.-M. (2012). Are new patterns of low-income distribution emerging in Canadian metropolitan areas? The Canadian Geographer/Le Geographe canadien, 56(3), 339-361.

Allen, J., \& Farber, S. (2019a, August). Benchmarking Transport Equity in the Greater Toronto and Hamilton Area (GTHA). Findings, 9934. doi: doi: 10.32866/9934

Allen, J., \& Farber, S. (2019b). Sizing up transport poverty: A national scale accounting of low-income households suffering from inaccessibility in Canada, and what to do about it. Transport Policy, 74, 214-223.

Allen, J., \& Farber, S. (2020). Planning transport for social inclusion: An accessibility-activity participation approach. Transportation Research Part D: Transport and Environment, 78, 102212.

Allen, J., \& Farber, S. (2021). Suburbanization of transport poverty. Annals of the Association of American Geographers, (in press).

Amar, A. K., \& Teelucksingh, C. (2015). Environmental Justice, Transit Equity and the Place for Immigrants in Toronto. Canadian Journal of Urban Research, 24(2), 43-63. 
Asanin, J., \& Wilson, K. (2008, March). "I spent nine years looking for a doctor": Exploring access to health care among immigrants in Mississauga, Ontario, Canada. Social Science $\mathcal{E}$ Medicine, 66(6), 1271-1283. doi: doi: 10.1016/j.socscimed.2007.11.043

August, M., \& Walks, A. (2018). Gentrification, suburban decline, and the financialization of multi-family rental housing: The case of Toronto. Geoforum, 89, 124-136.

Australian Bureau of Statistics. (2016a). 2016 census table builder - personal income and citizenship status in Greater Sydney. Retrieved from https://www.abs.gov.au/websitedbs/ censushome.nsf/home/tablebuilder

Australian Bureau of Statistics. (2016b, August). Census of Population and Housing: Census Dictionary, 2016 - Year of Arrival in Australia (YARP). https://www.abs.gov.au/ausstats/abs@.nsf/Lookup/2901.0Chapter59502016. c=AU; $\mathrm{o}=$ Commonwealth of Australia; ou=Australian Bureau of Statistics.

Australian Bureau of Statistics. (2016c, July). Main Features - Greater Capital City Statistical Areas (GCCSA). https://www.abs.gov.au/websitedbs/censushome.nsf/home/factsheetsgeography/\$file /Greater\%20Capital\%20City\%20Statistical\%20Area\%20-\%20Fact\%20Sheet.pdf. c=AU; $\mathrm{o}=$ Commonwealth of Australia; ou=Australian Bureau of Statistics.

Bangura, M., \& Lee, C. L. (2019). The differential geography of housing affordability in sydney: a disaggregated approach. Australian Geographer, 50(3), 295-313.

Barajas, J. M., Agrawal, A. W., \& Chatman, D. G. (2018). Immigration, income, and public transit perceptions: Findings from an intercept survey. Journal of Public Transportation, 21(2).

Barri, E. Y., Farber, S., Kramer, A., Jahanshahi, H., Allen, J., \& Beyazit, E. (2021). Can transit investments in low-income neighbourhoods increase transit use? exploring the nexus of income, car-ownership, and transit accessibility in toronto. Transportation Research Part D: Transport and Environment, 95, 102849.

Bartzokas-Tsiompras, A., \& Photis, Y. N. (2019, July). Measuring rapid transit accessibility and equity in migrant communities across 17 European cities. International Journal of Transport Development and Integration, 3(3), 245-258. doi: doi: 10.2495/TDI-V3-N3-245-258

Bauder, H., \& Sharpe, B. (2002). Residential segregation of visible minorities in Canada's gateway cities. The Canadian Geographer / Le Géographe canadien, 46(3), 204-222. doi: doi: 10.1111/j.1541-0064.2002.tb00741.x

Blumenberg, E., \& Evans, A. (2010, June). Planning for Demographic Diversity: The Case of Immigrants and Public Transit. Journal of Public Transportation, 13(2). doi: doi: 10.5038/ 2375-0901.13.2.2

Blumenberg, E., \& Smart, M. (2010, May). Getting by with a little help from my friends... and family: Immigrants and carpooling. Transportation, 37(3), 429-446. doi: doi: 10.1007/ s11116-010-9262-4

Boese, M., \& Phillips, M. (2017). The role of local government in migrant and refugee settlement in regional and rural australia. Australian Journal of Social Issues, 52(4), 388-404.

Bose, P. S. (2014, April). Refugees in Vermont: Mobility and acculturation in a new immigrant destination. Journal of Transport Geography, 36, 151-159. doi: doi: 10.1016/j.jtrangeo.2014 .03 .016

Bourne, L. S., \& Rose, D. (2001). The changing face of Canada: The uneven geographies of population and social change. Canadian Geographer/Le Géographe canadien, 45(1), 105-119.

Boyd, M., \& Vickers, M. (2000). 100 years of immigration in Canada. Canadian Social Trends(11), 12.

Burnley, I. (2005). Immigration and housing in an emerging global city, sydney, australia. Urban Policy and research, 23(3), 329-345. 
Burnley, I. H. (2001). The impact of immigration on Australia: A demographic approach. South Melbourne, Vic.; Oxford; New York: Oxford University Press.

Castree, N., Kitchin, R., \& Rogers, A. (2013). A Dictionary of Human Geography. OUP Oxford.

Clark, W. A. V., \& Wang, W. W. (2010, May). The Automobile, Immigrants, and Poverty: Implications for Immigrant Earnings and Job Access. Urban Geography, 31(4), 523-540. doi: doi: 10.2747/0272-3638.31.4.523

Cui, B., Boisjoly, G., Miranda-Moreno, L., \& El-Geneidy, A. (2020, March). Accessibility matters: Exploring the determinants of public transport mode share across income groups in Canadian cities. Transportation Research Part D: Transport and Environment, 80, 102276. doi: doi: $10.1016 / \mathrm{j} \cdot \operatorname{trd} .2020 .102276$

Ehrenhalt, A. (2012). The Great Inversion and the Future of the American City. New York: Vintage.

El-Geneidy, A. M., \& Levinson, D. M. (2006). Access to Destinations: Development of Accessibility Measures.

Farber, S., \& Marino, M. G. (2017). Transit accessibility, land development and socioeconomic priority: A typology of planned station catchment areas in the greater toronto and hamilton area. Journal of Transport and Land Use, 10(1), 879-902.

Farber, S., Mifsud, A., Allen, J., Widener, M. J., Newbold, K. B., \& Moniruzzaman, M. (2018, April). Transportation barriers to Syrian newcomer participation and settlement in Durham Region. Journal of Transport Geography, 68, 181-192. doi: doi: 10.1016/ j.jtrangeo.2018.03.014

Farrell, C. R. (2016, January). Immigrant suburbanisation and the shifting geographic structure of metropolitan segregation in the United States. Urban Studies, 53(1), 57-76. doi: doi: $10.1177 / 0042098014558537$

Fukuyama, F., \& Gocek, N. (2019, July). Immigration and populism in Canada, Australia, and the United States.

Geurs, K. T., \& Van Wee, B. (2004). Accessibility evaluation of land-use and transport strategies: Review and research directions. Journal of Transport geography, 12(2), 127-140.

Gibson, V. (2021). More than 81,000 households are waiting for subsidized housing in toronto. the city hopes a new waitlist system will help fill its units faster. Toronto Star. Retrieved from https://www.thestar.com/news/gta/2021/01/19/ more-than-81000-households-are-waiting-for-subsidized-housing-in-toronto -the-city-hopes-a-new-waitlist-system-will-help-fill-its-units-faster.html

Good, K. (2005, September). Patterns of Politics in Canada's Immigrant-Receiving Cities and Suburbs. Policy Studies, 26(3-4), 261-289. doi: doi: 10.1080/01442870500198312

Green, A. G., \& Green, D. A. (1999). The Economic Goals of Canada's Immigration Policy: Past and Present. Canadian Public Policy / Analyse de Politiques, 25(4), 425-451. doi: doi: $10.2307 / 3552422$

Griffith, D. A. (2003). Spatial Autocorrelation and Spatial Filtering: Gaining Understanding Through Theory and Scientific Visualization. Springer Science \& Business Media.

Hansen, W. G. (1959). How accessibility shapes land use. Journal of the American Institute of planners, 25(2), 73-76.

Heisz, A., \& Schellenberg, G. (2004). Public Transit Use Among Immigrants. Canadian Journal of Urban Research, 13(1), 170-191.

Hiebert, D. (2000). Immigration and the changing Canadian city. The Canadian Geographer / Le Géographe canadien, 44(1), 25-43. doi: doi: 10.1111/j.1541-0064.2000.tb00691.x

Hiebert, D. (2017). Immigrants and refugees in the housing markets of montreal, toronto and vancouver, 2011. Canadian Journal of Urban Research, 26(2), 52-78.

Hochstenbach, C., \& Musterd, S. (2018). Gentrification and the suburbanization of poverty: Changing urban geographies through boom and bust periods. Urban Geography, 39(1), 
26-53.

HousingAnywhere. (2020). HousingAnywhere's Top 100 Most Expensive Cities In The World 2020. Retrieved from https://housinganywhere.com/most-expensive-cities-in-the -world\# : : text=Hong\%20Kong\%20is \%20 often\%20mentioned, \%2Dbedroom\%20apartment \% $2 \mathrm{C} \% 20$ including $\% 20$ utilities .

Huang, J., Levinson, D., Wang, J., Zhou, J., \& Wang, Z.-j. (2018). Tracking job and housing dynamics with smartcard data. Proceedings of the National Academy of Sciences, 115(50), 12710-12715.

Hunter, F. (2017). Half of australia's 12,000 syrian and iraqi refugees to be settled by just one sydney council. The Sydney Morning Herald. Retrieved from https://www.smh.com.au/ politics/federal/half-of-australias-12000-syrian-and-iraqi-refugees-to-be -settled-by-just-one-sydney-council-20170116-gts7i0.html

Johnston, R., Forrest, J., \& Poulsen, M. (2001, July). Sydney's Ethnic Geography: New approaches to analysing patterns of residential concentration. Australian Geographer, 32(2), 149-162. doi: doi: 10.1080/00049180123731

Kazemipur, A., \& Halli, S. (2000). The invisible barrier: Neighbourhood poverty and integration of immigrants in Canada. Journal of International Migration and Integration; Dordrecht, 1(1), 85-100. doi: doi: http://dx.doi.org/10.1007/s12134-000-1009-1

Kneebone, E., \& Garr, E. (2010). The suburbanization of poverty. Washington, DC: Brookings Institute.

Levinson, D. M., \& Wu, H. (2020). Towards a general theory of access. Journal of Transport and Land Use, 13(1), 129-158. doi: doi: 10.5198/jtlu.2020.1660

Ley, D. (1999). Myths and Meanings of Immigration and the Metropolis. The Canadian Geographer / Le Géographe canadien, 43(1), 2-19. doi: doi: 10.1111/j.1541-0064.1999.tb01357.x

Liu, C. Y., \& Painter, G. (2012, April). Immigrant Settlement and Employment Suburbanisation in the US: Is There a Spatial Mismatch? Urban Studies, 49(5), 979-1002. doi: doi: 10.1177/ 0042098011405695

Lo, L., Shalaby, A., \& Alshalalfah, B. (2011, December). Relationship between Immigrant Settlement Patterns and Transit Use in the Greater Toronto Area. Journal of Urban Planning and Development, 137(4), 470-476. doi: doi: 10.1061/(ASCE)UP.1943-5444.0000080

Lucas, K. (2012). Transport and social exclusion: Where are we now? Transport policy, 20, 105-113.

Lussier-Tomaszewski, P., \& Boisjoly, G. (2021, January). Thinking regional and acting local: Assessing the joint influence of local and regional accessibility on commute mode in Montreal, Canada. Journal of Transport Geography, 90, 102917. doi: doi: 10.1016/j.jtrangeo .2020 .102917

Martens, K. (2016). Transport justice: Designing fair transportation systems. Routledge.

Massey, D. S. (1985). Ethnic Residential Segregation : A Theoretical Synthesis and Empirical Review. Ethnic Residential Segregation: A Theoretical Synthesis and Empirical Review, 69(3), 315-350.

McFadden, D. (1974, November). The measurement of urban travel demand. Journal of Public Economics, 3(4), 303-328. doi: doi: 10.1016/0047-2727(74)90003-6

Moniruzzaman, M., \& Páez, A. (2012). Accessibility to transit, by transit, and mode share: Application of a logistic model with spatial filters. Journal of Transport Geography, 24, 198-205.

Moovit Insights. (2020). Facts and usage statistics about public transit in sydney, australia. Retrieved from https://moovitapp.com/insights/en/Moovit_Insights_Public_Transit _Index_Australia_Sydney-442 
Morris, A. (2018). The financialisation of housing and the housing affordability crisis in sydney. Housing Finance International.

Mulley, C., Ma, L., Clifton, G., \& Tanner, M. (2017, January). Are Network Planning Guidelines Based on Equal Access Equitable? Transportation Research Record, 2651(1), 1-11. doi: doi: 10.3141/2651-01

Owen, A., \& Levinson, D. M. (2015). Modeling the commute mode share of transit using continuous accessibility to jobs. Transportation Research Part A: Policy and Practice, 74, 110122.

Randolph, B. (2006). Delivering the compact city in australia: current trends and future implications. Urban policy and research, 24(4), 473-490.

Randolph, B., \& Tice, A. (2014). Suburbanizing disadvantage in Australian cities: Sociospatial change in an era of neoliberalism. Journal of urban affairs, 36(sup1), 384-399.

Sarkar, S., Wu, H., \& Levinson, D. M. (2020). Measuring polycentricity via network flows, spatial interaction and percolation. Urban Studies, 57(12), 2402-2422.

Saxe, S., Miller, E., \& Farber, S. (2017). Regional accessibility and mode choice in the greater toronto hamilton area. In World society of transport and land use symposium, brisbane, australia.

Shin, E. J. (2017, December). Unraveling the Effects of Residence in an Ethnic Enclave on Immigrants' Travel Mode Choices. Journal of Planning Education and Research, 37(4), 425443. doi: doi: $10.1177 / 0739456 X 16663309$

Smart, M. J. (2015, January). A nationwide look at the immigrant neighborhood effect on travel mode choice. Transportation, 42(1), 189-209. doi: doi: 10.1007/s11116-014-9543-4

Statistics Canada, G. o. C. (2016a). Data tables, 2016 census, immigrant status and period of immigration (10), income statistics (17), age (10) and sex (3) for the population aged 15 years and over in private households of canada, provinces and territories, census metropolitan areas and census agglomerations, 2016 census - $25 \%$ sample data. Retrieved from https://ww112.statcan.gc.ca/census-recensement/2016/dp-pd/dt-td/ Rp-eng. $c f m ? T A B I D=2 \& L A N G=E \& A P A T H=3 \& D E T A I L=0 \& D I M=0 \& F L=A \& F R E E=0 \& G C=0 \& G K=0 \& G R P=$ $1 \& P I D=110560 \& P R I D=10 \& P T Y P E=109445 \& S=0 \&$ SHOWALL=0\&SUB=0\&Temporal=2017\&THEME= $120 \&$ VID $=0 \&$ VNAMEE $=\&$ VNAMEF $=$

Statistics Canada, G. o. C. (2016b). Data tables, 2016 census, main mode of commuting (20), commuting duration (7), time leaving for work (7), sex (3) and age (11b) for the employed labour force aged 15 years and over having a usual place of work or no fixed workplace address, in private households of canada, provinces and territories, census metropolitan areas and census agglomerations, 2016 census - $25 \%$ sample data. Retrieved from https://ww112.statcan.gc.ca/census-recensement/2016/dp-pd/dt-td/ Rp-eng. $c f m ? T A B I D=2 \& L A N G=E \& A P A T H=3 \& D E T A I L=0 \& D I M=0 \& F L=A \& F R E E=0 \& G C=0 \& G K=0 \& G R P=$ $1 \& \mathrm{PID}=110711 \& \mathrm{PRID}=10 \& \mathrm{PTYPE}=109445 \& \mathrm{~S}=0 \&$ SHOWALL=0\&SUB=0\&Temporal=2017\&THEME $=$ $125 \& V I D=0 \&$ VNAMEE $=\&$ VNAMEF $=$

Statistics Canada, G. o. C. (2016c, November). Dictionary, Census of Population, 2016 Census metropolitan area (CMA) and census agglomeration (CA). https://www12.statcan.gc.ca/census-recensement/2016/ref/dict/geo009-eng.cfm.

Statistics Canada, G. o. C. (2017, May). Dictionary, Census of Population, 2016 - Year of immigration. https://www12.statcan.gc.ca/census-recensement/2016/ref/dict/pop133-eng.cfm.

Tal, G., \& Handy, S. (2010, March). Travel behavior of immigrants: An analysis of the 2001 National Household Transportation Survey. Transport Policy, 17(2), 85-93. doi: doi: 10 .1016/j.tranpol.2009.11.003

Troy, L., Randolph, B., Pinnegar, S., Crommelin, L., \& Easthope, H. (2020). Vertical sprawl in the australian city: Sydney's high-rise residential development boom. Urban Policy and 
Research, 38(1), 18-36.

Vezina, M., \& Houle, R. (2017). Settlement patterns and social integration of the population with an immigrant background in the montreal, toronto and vancouver metropolitan areas. Ethnicity, Language and Immigration Thematic Series.

Wang, L. (2007, September). Immigration, ethnicity, and accessibility to culturally diverse family physicians. Health $\mathcal{E}$ Place, 13(3), 656-671. doi: doi: 10.1016/j.healthplace.2006.10 .001

Wu, H., Avner, P., Boisjoly, G., Braga, C. K. V., El-Geneidy, A., Huang, J., .. Levinson, D. (2021). Urban access across the globe: An international comparison of different transport modes. Nature Urban Sustainability, in press.

Wu, H., \& Levinson, D. (2020). Unifying access. Transportation Research Part D: Transport and Environment, 83, 102355.

Wu, H., Levinson, D., \& Owen, A. (2019, November). Commute mode share and access to jobs across US metropolitan areas. Environment and Planning B: Urban Analytics and City Science, 2399808319887394. doi: doi: 10.1177/2399808319887394

Xi, Y. L., Allen, J., Miller, E. J., Farber, S., \& Keel, R. (2020, April). Importance of Automobile Mode Share in Understanding the Full Impact of Urban Form on Work-Based Vehicle Distance Traveled. Transportation Research Record, 2674(4), 222-234. doi: doi: 10.1177/ 0361198120911053

Zhang, M. L., \& Pryce, G. (2020, August). The dynamics of poverty, employment and access to amenities in polycentric cities: Measuring the decentralisation of poverty and its impacts in England and Wales. Urban Studies, 57(10), 2015-2030. doi: doi: 10.1177/ 0042098019860776

Zhuang, Z. C., \& Chen, A. X. (2017, July). The role of ethnic retailing in retrofitting suburbia: Case studies from Toronto, Canada. Journal of Urbanism: International Research on Placemaking and Urban Sustainability, 10(3), 275-295. doi: doi: 10.1080/17549175.2016.1254671

\section{Appendix}

Replication of Table 2 but using a 30 minute threshold rather than 45 minutes in the accessibility computation.

Table 4: Average accessibility $\left(\bar{A}_{c}\right)$ (for number of jobs reachable within 30 minutes) and relative accessibility ratios $\left(R_{c}\right)$ for recent immigrants (2011-2016) from different countries, $c$

\begin{tabular}{llllllll}
\hline \multicolumn{4}{l}{ Sydney } & & & & Toronto \\
Country of birth $(c)$ & Total $(\%)$ & $\bar{A}_{c}$ & $R_{\mathcal{c}}$ & Home country $(c)$ & Total $(\%)$ & $\bar{A}_{c}$ & $R_{\mathcal{c}}$ \\
\hline China & $63,500(17.2 \%)$ & 131 & 2.46 & India & $58,800(16.5 \%)$ & 158 & 0.85 \\
India & $43,200(11.7 \%)$ & 85 & 1.59 & China & $49,900(14.0 \%)$ & 188 & 1.13 \\
United Kingdom & $22,100(6.0 \%)$ & 127 & 2.36 & Philippines & $43,300(12.1 \%)$ & 241 & 1.01 \\
Iraq & $12,500(3.4 \%)$ & 39 & 0.72 & Pakistan & $21,800(6.1 \%)$ & 149 & 0.69 \\
Philippines & $12,300(3.3 \%)$ & 71 & 1.31 & Iran & $18,800(5.3 \%)$ & 271 & 1.33 \\
South Korea & $11,000(3.0 \%)$ & 142 & 2.62 & Iraq & $8,200(2.3 \%)$ & 138 & 0.62 \\
New Zealand & $10,800(2.9 \%)$ & 83 & 1.53 & USA & $8,000(2.2 \%)$ & 258 & 1.54 \\
Pakistan & $10,400(2.8 \%)$ & 58 & 1.07 & Jamaica & $7,300(2.1 \%)$ & 149 & 0.70 \\
Vietnam & $9,600(2.6 \%)$ & 74 & 1.37 & Sri Lanka & $7,400(2.1 \%)$ & 134 & 0.63 \\
Iran & $7,800(2.1 \%)$ & 73 & 1.36 & Bangladesh & $6,800(1.9 \%)$ & 317 & 1.14 \\
\hline All immigrants & $370,100(100 \%)$ & 109 & 2.20 & All immigrants & $356,900(100 \%)$ & 210 & 1.10 \\
\hline
\end{tabular}

